\title{
CRISIS: RECUPERACIÓN CON MAYOR DESEMPLEO E INFORMALIDAD
}

\section{CRISIS: RECOVERY WITH HIGHER UNEMPLOYMENT AND INFORMALITY}

\section{Beatriz Herrera García*}

\author{
Docente Principal de la Facultad de Ciencias Contables, UNMSM
}

[Recepción: Febrero de 2010 / Conformidad: Abril de 2010]

\begin{abstract}
RESUMEN
La intensificación de la crisis mundial cobra un elevado precio en el nivel de empleo de todos los países. Desde el 2008 se ha observado un rápido aumento del desempleo, y se prevé que la situación empeorará en el 2009 y el 2010. Las proyecciones sitúan el aumento del desempleo (flow) en 61 millones de trabajadores en el 2009, ascendiendo el stock de los trabajadores desempleados a $240 \mathrm{mi}$ llones, alcanzándose el desempleo más alto de la historia según la OIT. Es posible que las elevadas tasas de desempleo persistan durante mucho tiempo. La experiencia adquirida en anteriores crisis mundiales indica que suelen necesitarse entre cuatro y cinco años para que las tasas de desempleo vuelvan a niveles anteriores a la crisis una vez comenzada la recuperación. Ello se debe a que los incrementos masivos del desempleo a largo plazo y la mayor informalidad del mercado laboral son muy difíciles de invertir. Si estas tendencias se afianzan, los efectos negativos de la crisis serán muy duraderos.
\end{abstract}

Palbras clave: Desempleo, flow, stock, crecimiento, informalidad, tasas.

\begin{abstract}
The deepening of the global world crisis charged a heavy toll on employment worlwide. A rapid rise in the unemployment has been witnessed since 2008 and is expected to worsen in 2009 and 2010. The proyections put the rise in unemployment (flow) at 61 million over in 2009, also rise higher unemployment stock at 240 million, but as the situation continues to deteriorate this number will be historical highdest unemployment, source OIT. Probably higher unemployment rates may persist for some time. Lessons from past world crisis indicate that it typically takes four or five years for unemployment rates to return to pre-crisis levels after economic recovery has set in. This is because massive rises in log-term unemployment and greater labour market informalization are very difficult to reverse. If these trends take root, the negative effects of the crisis will be long-lasting.
\end{abstract}

Keywords: Unemployment, flow, stock, growth, informality rates.

\footnotetext{
* Doctora en Ciencias Económicas, UNMSM. Ex Vicerrectora Administrativa, UNMSM. Docente investigadora de la Facultad de Ciencias Contables, UNMSM. E-mail: bherrerag@unmsm.edu.pe
} 


\section{BREVE HISTORIA DE LA PEOR CRISIS DESDE LA GRAN DEPRESIÓN}

Lo que al inicio pareció una leve grieta del mercado inmobiliario de los Estados Unidos durante el verano de 2007, se vislumbró, luego, como una profunda fisura del sistema financiero mundial, causando el desmoronamiento de importantes instituciones bancarias, la caída en picada de los mercados de valores (bolsas de valores) y un congelamiento crediticio generalizado.

En efecto, el factor desestabilizador de la crisis financiera fue la aguda desvalorización de los activos inmobiliarios en los Estados Unidos. El creciente aumento de estos precios comenzó a desacelerarse en el 2006, por efecto del endurecimiento de la política monetaria norteamericana ${ }^{1}$, y su nivel empezó a disminuir a principios de 2007. Un año después el índice del precio de las viviendas en ese país se situaba un 18 por ciento por debajo de su nivel, ejerciendo fuertes presiones sobre el balance de los deudores hipotecarios y de las entidades financieras. Los esquemas de refinanciamiento (obligado) de los intermediarios se vieron obstaculizados por crecientes problemas de morosidad y por la desvalorización de los activos de respaldo, lo que afectó la violenta elevación de la carga relativa de los pasivos.

La evidencia de que se había producido una descapitalización de diversos instrumentos de inversión pertenecientes a importantes instituciones financieras internacionales fue lo que cerró sus posibilidades de endeudamiento en mercados de corto plazo e inter- bancarios. Ante esta situación, los prestamistas se mostraron reticentes a desprenderse de liquidez, con lo que empezó a generarse una profunda contracción crediticia.

$\mathrm{Al}$ anterior factor deflacionario se sumó un segundo, se produjo con los activos bursátiles: el nivel del índice Dow Jones ${ }^{2}$-en noviembre de 2008- se situó en un nivel de 35.4 por ciento menor que en el mes de julio de 2007, antes que se desencadenara la gran crisis. Los flujos privados de financiamiento de déficit de la cuenta corriente de la balanza de pagos norteamericana se redujeron notablemente, aunque permanecieron positivos. Entre 2003 y el tercer trimestre de 2007 representaron en promedio -los flujos privados- un $2.6 \%$ del PBI, en cambio, entre el cuarto trimestre de 2007 y el segundo trimestre de 2008 alcanzaron apenas un 0.6 por ciento del PBI, dejando el financiamiento del déficit externo corriente de Estados Unidos, pendiente de los flujos oficiales, que cubrieron el $90 \%$ del saldo total, equivalente al 5 por ciento del PBI.

Un tercer factor deflacionario surgió con la consolidación de las tendencias recesivas en el Japón (segunda economía más importante del mundo) y en la zona del euro, y la apreciación del dólar a partir de mediados de 2008, que provocaron la caída de los precios de los productos básicos (commodities), tendencia fortalecida por el marcado debilitamiento de la economía de Estados Unidos.

Por otro lado, la quiebra de Lehman Brothers Holdings Inc., marcó un punto de inflexión en el desarrollo de la crisis, sus repercusiones financieras como un mecanismo

1 Durante la primera mitad de 2008, el dólar se había depreciado pronunciadamente sobre todo respecto al euro, pero luego la tendencia cambió bruscamente. En particular, las monedas de los países exportadores de materias primas han caído bruscamente con respecto al dólar en la segunda mitad de 2008. Sin embargo, el fortalecimiento del dólar sería efímero por la persistencia a la tendencia de un aterrizaje forzoso en 2009 y, en adelante, debido al déficit externo de EE.UU., que se encuentra aún muy alto y su balance financiero externo negativo no deja de crecer.

2 El índice Dow Jones representa a las 30 acciones industriales más representativas de los Estados Unidos. 
Gráfico N.o 1. Alza y caída de los precios de los commodities en 2006 y 2008.

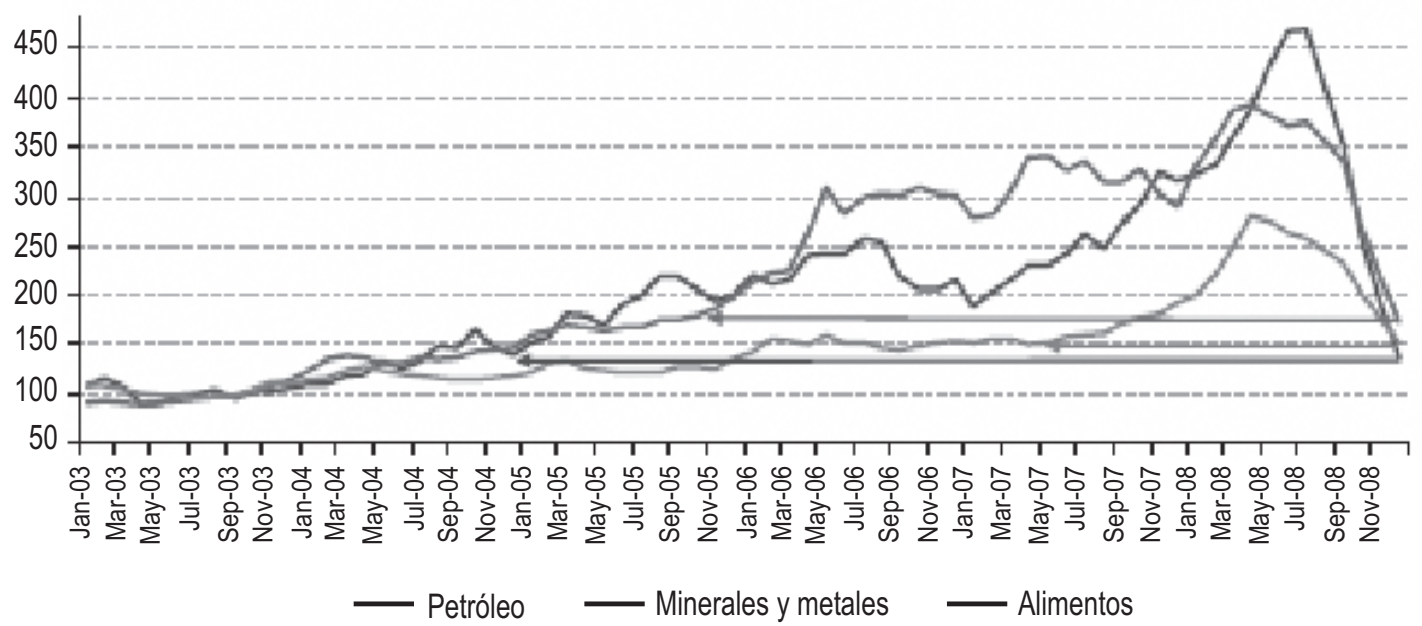

coordinado de expectativas negativas acabó por generar un pánico generalizado. Se produjo una virtual paralización de los mercados de crédito y una demanda infinita de liquidez, situación que se hizo patente sobre todo en los mercados interbancarios, lo cual ayudó a deteriorar aún más los balances bancarios y puso en duda la supervivencia de las grandes entidades, además de alimentar temores de una falla sistémica de los mercados financieros mundiales.

En consecuencia, el desenvolvimiento de la gran crisis mundial -afectado por los factores deflacionarios- ha provocado una disminución generalizada de todas las actividades económicas y financieras afectando al producto bruto mundial con una tasa negativa del 2.2 por ciento en el 2009 (la primera contracción desde la Segunda Guerra Mundial). La crisis ha provocado una desaceleración brusca con respecto a la tasa de crecimiento de 2.5 por ciento de 2008 (ver gráfica 2), que resultó ser una tasa muy por debajo de las tasas experimentadas en años anteriores (2004-2007).

Sin embargo, debido a las condiciones actuales, da lugar a pensar en la seria posi- bilidad de un escenario pesimista sobre la recuperación. Si la contracción del crédito internacional se prolonga y la confianza en el sistema financiero no se restaura, los países desarrollados enfrentarán una profunda recesión económica en 2009 y 2010.

Según la tendencia de la economía mundial el crecimiento económico en los países en desarrollo se ralentizará a una tasa de 2 por ciento en el 2009, esta tasa se sitúa, en cualquier caso, a un nivel bastante inferior al alcanzado antes de la crisis, cuando se registraba una tasa promedio de $7 \%$ anual, perjudicando así los esfuerzos de la lucha contra la pobreza y la necesidad de asegurar la estabilidad social y política.

Ante ese panorama sombrío, Naciones Unidas recomienda, para evitar el riesgo de una recesión profunda y generalizada, poner en marcha mecanismos de reactivación económica de gran escala previamente coordinados internacionalmente, a fin de crear las sinergias que la situación crítica exige; sin embargo, estas medidas de reactivación deberán ser consistentes con las aspiraciones de un desarrollo económico sostenido de las naciones. 
Gráfico N.o 2. La economía mundial en recesión en 2009

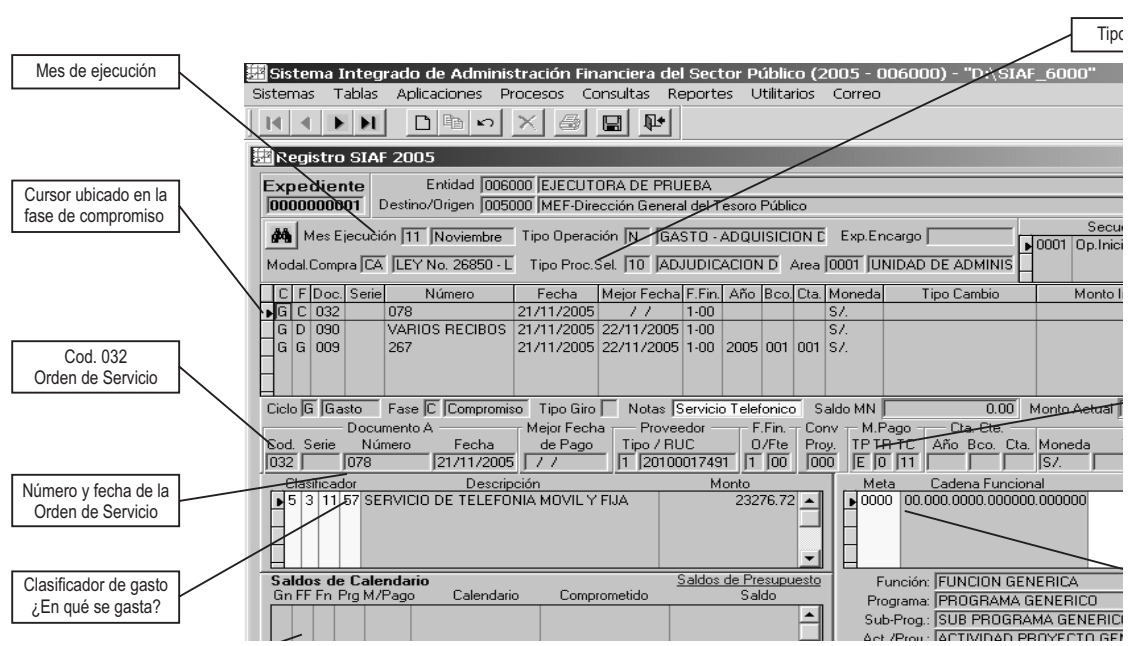

Fuente: Rob Vos, WESP 2009, New York.

Los mecanismos de reactivación propuestos comprenden: inyecciones de liquidez, medidas de re-capitalización y un estímulo fiscal efectivo del orden de 1.5 a 2.0 por ciento del producto bruto interno. Todo ello debido al costo de los préstamos externos cuyo rápido aumento (desde el cuarto trimestre de 2008), ha tomado por sorpresa a los formuladores de política en los países en desarrollo, a esta nueva situación se suma el hecho dramático de las salidas de capital, de las bolsas de valores que han bajado, mientras que los mercados de dinero y de artículos comerciales se han vuelto extremadamente volátiles.

Por otro lado, el tipo de cambio se esta depreciando firmemente en varios países y los precios de los principales artículos de consumo han bajado de los elevados niveles del año pasado, junto con el desarrollo de las exportaciones en rápido des-aceleramiento que están provocando saldos de cuentas corrientes de muchos países con números rojos.

Cuadro N.o 1. Tasa de crecimiento del producto mundial y economías desarrolladas en 2008 y 2009.

\begin{tabular}{|l|l|l|l|}
\hline & \multicolumn{1}{|c|}{ 2000-2008 } & \multicolumn{1}{|c|}{$\mathbf{2 0 0 8}$} & \multicolumn{1}{|c|}{$\mathbf{2 0 0 9}$} \\
\hline Economía Mundial & & & \\
Economías Desarrolladas & n.d. & 0.17 & -2.2 \\
-Estados Unidos & 2.2 & 0.5 & -3.5 \\
-Japón & 2.4 & 0.4 & -2.5 \\
Unión Europea (UE) & 1.4 & -0.7 & -5.6 \\
-Francia & 2.2 & 0.8 & -4.1 \\
-Alemania & 1.9 & 0.4 & $-2-2$ \\
-Inglaterra & 1,5 & 1.3 & -4.8 \\
Resto de Europa & 2.5 & 0.6 & -4.5 \\
Memorandum: & 2.3 & 1.9 & -2.0 \\
América del Norte & 2.4 & 0.4 & -2.5 \\
Europa Occidental & 2.2 & 0.8 & -4.0 \\
Asia y Oceanía & 1.7 & -0.3 & -4.6 \\
Principales Economías Desarrolladas & 2.0 & 0.3 & -3.6 \\
\hline
\end{tabular}

Fuente: OECD, Main Economic Indicators, París, 2009. 


\section{LA CRISIS EN LA REGIÓN LATINOAMERICANA}

La desaceleración del crecimiento de la economía mundial afectó negativamente a la demanda de empleo y se estima que la tasa de desempleo en toda la región se incremente a 8.3 por ciento, con un deterioro de la calidad de los puestos de trabajo.

Tal como se afirmó (supra), la economía mundial enfrenta la crisis más profunda de los últimos 60 años $^{3}$, siendo sus manifestaciones más negativas: el grado de volatilidad, el gran desempleo, el nerviosismo en los mercados financieros y los riesgos que atraviesa la economía mundial, e.g., los recientes sucesos ocurridos en los mercados inmobiliario y financiero de Dubai hacia fines de 2009 y sus inmediatas repercusiones en otros mercados, a partir de los temores por los elevados niveles de exposición de varios bancos europeos.

En la región. El producto bruto interno de América Latina arrojó resultados negativos en 2009 (-1.7\%), principalmente por efecto de la crisis financiera y económica internacional, asimismo, el impacto negativo se tradujo en una caída de $-2.8 \%$ en el bienestar de la población (caída del producto per cápita regional).

En particular, en América del Sur, se registró, en cambio, un pequeño aumento del producto bruto interno en $0.2 \%$ debido a las particularidades de sus exportaciones y el desempeño heterogéneo de sus países.

A lo largo del 2009, la actividad económica latinoamericana enfrentó los efectos del dramático cambio en el escenario económico internacional. A inicios del 2008, Latinoamérica en su conjunto atravesaba por un fuerte dinamismo económico impulsado por la demanda externa (exportaciones), el aumento de las importaciones apoyadas en la depreciación de dólar y el aumento de la demanda interna (consumo e inversiones). A fines del 2008, se produjo un cambio de tendencia brusco debido a la aguda y repentina caída de la demanda externa, con una contracción fuerte de las exportaciones, aunado a una significativa disminución de los precios de las exportaciones de la región, y en medio de un contexto de dificultades de acceso al crédito debido a la disminución en la oferta y a las tasas de interés más elevadas.

Cuadro N.o 2. Tasas de crecimiento en países de América del Sur.

\begin{tabular}{|l|c|}
\hline \multicolumn{1}{|c|}{ PAÍSES } & 2009 \\
\hline Argentina & 0.7 \\
Bolivia & 3.5 \\
Brasil & 0.6 \\
Colombia & 0.3 \\
Chile & -1.8 \\
Ecuador & -0.4 \\
Paraguay & -3.5 \\
Perú & 0.8 \\
Uruguay & 1.2 \\
Venezuela & -2.3 \\
\hline América del Sur & 0.2 \\
\hline
\end{tabular}

Fuente: CEPAL, Santiago de Chile, 2009.

3 La fuerza de la crisis provocará que tanto el comercio como la producción mundial se contraigan intensamente: en 19\% el comercio mundial y en $2.2 \%$ el producto mundial. Para contrarrestar estos efectos nocivos de la crisis, los principales bancos centrales del mundo coordinan la aplicación de políticas monetarias expansivas. 
Durante el 2009, la región enfrentaba un escenario de elevada incertidumbre sobre el futuro de la crisis del sistema financiero internacional, de la capacidad de recuperación de las economías desarrolladas y la evolución futura de los precios de los commodities. Asimismo, se generó un cambio en las expectativas de los agentes económicos traduciéndose en una caída del gasto total. También se produjo una fuerte caída del consumo debido a la incertidumbre laboral y a la disminución de las remesas del exterior.

\section{El aumento del desempleo}

En el 2009, la acentuada crisis provocó la disminución de la formación bruta del capital fijo (FBKF), empeorando así las condiciones del mercado del trabajo. Se produjo un aumento de la tasa de desempleo del $7.4 \%$ al $8.3 \%$, así como la caída de empleo (-0.6\%), esta fue una tendencia generalizada para todos los países de la región.

Es de mencionar que la caída de la tasa de empleo se dio en ausencia de redes de protección, lo que provocó que muchas personas se vieran obligadas a emplearse en condiciones críticas, muy distantes de sus preferencias ${ }^{4}$. Durante el año de crisis, la fuerte caída de la actividad económica y de la inversión en toda Latinoamérica desalentó la demanda de empleo, lo que se expresó en una brusca caída del empleo asalariado.

Por otro lado, la calidad del empleo registró una caída, produciéndose una baja importante de la demanda laboral y una pérdida de dinamismo de la generación del empleo formal y un aumento del empleo informal. El deterioro de las condiciones laborales también se expresó en el aumento de la tasa de subempleo por horas.

En la región en su conjunto, el incremento de la tasa de desempleo de $7.4 \%$ a $8.3 \%$ representa un aumento del número de desempleados urbanos de 2,3 millones de trabajadores (flow), subiendo el número de personas en esta condición a aproximadamente 18,2 millones (stock).

Los sectores económicos más golpeados en términos de empleo fueron: la industria manufacturera, la construcción, el comercio, el turismo y los servicios financieros a las empresas. Asimismo, la crisis mundial acentuó la disminución de formación bruta de capital fijo debido a la paralización de importantes proyectos de inversión y a la drástica caída de la demanda de maquinarias y equipos importados debido al aumento de la capacidad ociosa, registrándose una fuerte disminución de las importaciones 5 .

\section{Las condiciones comerciales y financieras}

La actual crisis mundial ha provocado una caída importante de los volúmenes comerciales desde finales de 2008, asociada fundamentalmente al derrumbe de la demanda de importaciones en los países desarrollados. Los flujos de comercio se redujeron a tasas anualizadas de entre 30 y $50 \%$ (fines de 2008 y segundo trimestre de 2009), sin embargo, para el año 2009 en su conjunto el volumen descendió en aproximadamente un $13 \%$. A la caída libre de la demanda global se sumó una

4 Asimismo, la baja demanda laboral no agudizó el problema social, debido al autoempleo (empleo por cuenta propia), que se extendió en varios países de la región.

5 En América Latina, en el 2009, el sector agrícola mostró un leve descenso, el sector minero mostró un desempeño heterogéneo, la industria manufacturera fue el sector más afectado, el sector de la construcción registra una contracción, por lo que el valor de las importaciones de bienes de capital cayeron en: Argentina (35\%), Brasil (14\%), Perú (25.6\%), en México (23.4\%). 
considerable presión en los mercados financieros mundiales, generando un incremento en los costos de endeudamiento y una importante escasez de créditos comerciales.

Los precios de los commodities (bienes primarios) también observó una caída libre por efecto de la crisis. A inicios del 2009, los precios del petróleo se desplomaron desde sus niveles máximos de mediados del 2008; los precios de los metales se redujeron aún más drásticamente, en el mismo periodo, hasta casi un tercio de sus niveles máximos; los precios de los productos agrícolas, incluyendo los granos básicos, también se redujeron significativamente. Para el 2010, no se espera que la holgura en el suministro de estos productos (commodities) se vaya a eliminar en el futuro próximo mientras que, muy probablemente, solo se observará una leve recuperación en la demanda. Sin embargo, dada la estrecha relación entre los precios de los productos básicos y los mercados financieros, incluyendo el tipo de cambio del dólar, probablemente provocará que estos precios se comporten de manera altamente volátil.

Los países en desarrollo, entre ellos los latinoamericanos, han sufrido fuertes oscilaciones en sus términos de intercambio. Los exportadores netos de petróleo y minerales, en particular, han sufrido fuertes choques adversos en sus precios de exportación, además de la acelerada caída de la demanda mundial asociada a la crisis, pero recuperaron algo de terreno recientemente. Sin embargo, el revés más reciente en sus términos de intercambio hará más lenta su recuperación, porque como se mencionó persiste el problema general de una alta volatilidad de los términos de intercambio que dificulta la gestión macroeconómica e incrementa la inseguridad económica.

\section{LOS DESEQUILIBRIOS MUNDIALES}

El flujo neto de recursos financieros continúa siendo de países en desarrollo (países pobres) hacia países desarrollados (países ricos). Durante el 2009, los países en desarrollo en su conjunto, han proveído transferencias financieras netas a los países desarrollados por un valor de 568 miles de millones de dólares ${ }^{6}$. Este monto neto notable de transferencias es igual a los flujos netos de capital menos los pagos por rentas de inversión, refleja la dimensión de los desequilibrios mundiales como consecuencia de la crisis financiera y económica mundial.

Por otro lado, los flujos privados de capital extranjero hacia países en desarrollo disminuyeron drásticamente a partir de la segunda mitad del 2008. La mayor caída se produjo en los préstamos bancarios internacionales, de modo que lo que fue una significativa entrada de recursos a economías en desarrollo hasta la primera mitad del 2008 se transformó en una salida neta de capital durante el 2009.

Los países con altos déficits en cuenta corriente, y por lo tanto los más dependientes de capital extranjero, fueron los más afectados por el endurecimiento en las condiciones crediticias en los mercados internacionales. Las proyecciones para el 2010 indican que se espera que el acceso a préstamos bancarios siga siendo limitado para la mayor parte de los países en desarrollo por las apretadas condiciones de la oferta crediticia.

En efecto, la actual crisis financiera y la contracción de la economía mundial han conducido a un ajuste recesivo de los desequilibrios en cuenta corriente entre los países debido a que las importaciones en países deficitarios se redujeron sensiblemente y los

6 Este monto es significativamente inferior al máximo histórico de 891 mil millones de dólares observado durante el año 2008. 
ingresos de exportación en la mayoría de los países superavitarios se desplomaron. En la mayoría de los países superavitarios el crecimiento económico se sigue basando en exportaciones mientras se mantienen altas tasa de ahorro interno, consistentes con una demanda interna más débil y una considerable acumulación de reservas. En cambio, en la mayoría de los países deficitarios, el ahorro privado ha crecido en la medida en que los consumidores se tornan más cautelosos, sin embargo, dicho ahorro no llega todavía a compensar los crecientes déficits fiscales ni puede cubrir plenamente la creciente acumulación de deuda pública. De todo ello, se asume que los déficits externos y las necesidades de financiación externa en estos países podrían continuar creciendo, con lo que se produciría el resurgimiento de los desequilibrios mundiales y provocar un aterrizaje forzoso del dólar.

En los Estados Unidos, el nivel de endeudamiento externo ha aumentado notablemente, llegando a 3.8 billones de dólares en 2009, y se espera que siga creciendo durante $2010^{7}$, por lo que se prevé entonces que el dólar siga experimentando una fuerte presión a la baja. El dólar ha ido mostrando una tendencia a la baja de largo plazo desde el 2002, sin embargo, en el periodo segundo semestre del 2008 y primer trimestre del 2009, se observó una cierta apreciación. Tal apreciación se explica por el efecto fuga hacia la seguridad en el contexto de aversión al riesgo típico de una crisis financiera, lo que provocó movimientos masivos hacia la adquisición de bonos del Tesoro de EE.UU. Al observarse, desde marzo del 2009, ciertos esfuerzos de desapalancamiento de las grandes instituciones financieras han ido menguando y la caída del dólar ha retomado su curso. Esta situación se agrava por el hecho que los inversores empiezan a mostrar preocupación acerca del agravamiento del déficit fiscal y la posición externa de los Estados Unidos. Existe la preocupación que la tendencia a la baja del dólar dé lugar a una caída de la confianza en la moneda de reserva internacional, lo que conllevaría a una gran volatilidad en los mercados cambiarios, con el riesgo de movimientos aún más bruscos de las divisas más importantes y un aterrizaje forzoso del dólar.

La vuelta al equilibrio entre países es necesaria bajo la consideración que tanto la demanda de consumo como la inversión privada en los Estados Unidos se mantendrá rezagada al igual que en otras economías importantes debido a que las tasas de utilización del capital han bajado a niveles no experimentados hasta ahora. Entonces los incrementos de demanda en los países deficitarios tienen que venir de las exportaciones netas. Dichas exportaciones netas deberán ser absorbidas por los países superavitarios más grandes, empezando por China, India y otros países emergentes de Asia. Esto es posible si los estímulos fiscales de dichos países se fortalecen, lo que junto a una depreciación del dólar podría dar lugar a un incremento de las importaciones. Para ello además, tanto Alemania, Japón y otras grandes economías superavitarias tendrían que contribuir al reequilibrio mundial acentuando el gasto de inversión productiva en sectores domésticos. Lo mismo tendrían que hacer los grandes exportadores de petróleo, es decir, incrementar sus inversiones productivas en áreas que les

7 Estados Unidos, la primera economía del mundo y considerada la economía locomotora de la economía mundial, enfrenta retos históricos en la presente crisis iniciada en ese país, a la brecha externa mencionada se suma la tasa de desempleo más alta que supera el 10\% de la PEA y su déficit fiscal también bordea el 10\%, lo que fortalece la tesis del aterrizaje forzoso del dólar. 
permita una mayor diversificación de sus economías. Para todo ello se necesita fortalecer la coordinación de políticas y la reforma del sistema financiero mundial.

\section{EL SECTOR EXTERNO LATINOAMERICANO}

Los graves trastornos externos están teniendo gran impacto en el saldo de las balanzas de pagos de las economías en desarrollo. Antes que se desencadenara la crisis mundial, muchos países en desarrollo habían acumulado considerables reservas de divisas; sin embargo, a partir del 2008, una repentina inversión de las entradas de capital y el empeoramiento de la situación de cuenta corriente han producido una disminución de las reservas de muchos de ellos.

El comportamiento de la cuenta corriente de la balanza de pagos (brecha externa) de América Latina y El Caribe, resume la posición de la región en el mundo, se estima que en el 2009 dicha cuenta corriente cerrará con un déficit equivalente al 0.5 por ciento del producto bruto interno de la región, similar a los resultados del año 2008, que cerró con 0,6 por ciento del PBI regional. En los países sudamericanos, donde los ingresos de exportación se derivan principalmente del petróleo y minerales, precios más bajos de dichos productos, afectarán negativamente sus términos de intercambio.

La estimación del déficit de cuenta corriente de la región ha sido otro de los cambios de tendencia con respecto a años anteriores, en los que se experimentaron superavits o déficits relativamente bajos en algunos países, i.e., en países de América del Sur debido a la crisis mundial experimentaran superavits más bajos o déficits mayores que en los años anteriores.

El sector externo ${ }^{8}$ fue uno de los principales canales de transmisión de la crisis internacional del periodo 2008-2009 hacia Latinoamérica. El desarrollo de las pérdidas mensuales en el volumen de comercio de bienes a nivel mundial se reflejó en el comercio de la región latinoamericana. Por un lado, se redujo la demanda externa, i.e., las importaciones provenientes de América Latina en los mercados de Estados Unidos, de la Unión Europea y de China primero se desaceleraron y, luego, se redujeron en términos absolutos respecto del año anterior. En el segundo trimestre del 2009 estas caídas llegaron a su punto más profundo y desde entonces se puede observar cierta estabilización. Los cálculos estimados de la reducción de las exportaciones latinoamericanas son del 23.4 por ciento en precios corrientes en el 2009, equivalente al 9.6 por ciento en precios constantes. Por el otro, la reducción estimada en las importaciones es mayor, los cálculos arrojan un 24.4 por ciento en precios corrientes y un 16.3 por ciento en precios constantes. Esta fuerte disminución se explica principalmente por la reducción del consumo y las inversiones a nivel doméstico. La caída de las importaciones, hecho asociado a la menor demanda interna en el contexto de la crisis mundial, explica en gran parte el resultado en el saldo de la cuenta corriente (en otro contexto, las importaciones habrían aumentado agudizando el saldo de la cuenta corriente).

8 Es de considerar que el comercio de bienes ha sido una de las locomotoras de la economía mundial. El comercio global de bienes ha crecido a dos veces el ritmo del producto mundial durante el periodo 2004-2007, tanto en términos de volumen como de valor en dólares. Sin embargo, durante el ciclo de auge del comercio que comenzó en el 2001, el crecimiento del comercio de bienes ha sido liderado por los países desarrollados y países del Este de Asia, encabezado por China. 
Cuadro N.o 3. America Latina: Balanza de pagos 2007-2009

(En millones de dólares)

\begin{tabular}{|c|c|c|c|c|c|c|c|c|c|c|c|c|}
\hline \multirow{2}{*}{ Países } & \multicolumn{3}{|c|}{ Balanza comercial } & \multicolumn{3}{|c|}{$\begin{array}{c}\text { Balanza de cuenta } \\
\text { corriente }\end{array}$} & \multicolumn{3}{|c|}{$\begin{array}{l}\text { Balanza de capital y } \\
\text { financiera }\end{array}$} & \multicolumn{3}{|c|}{ Balanza global } \\
\hline & 2007 & 2008 & 2009 & 2007 & 2008 & 2009 & 2007 & 2008 & 2009 & 2007 & 2008 & 2009 \\
\hline AMERICA LATINA & 45.517 & 14.329 & 14.619 & 14.822 & -26.767 & -19.429 & 109.470 & 63.993 & 49.920 & 124.282 & 37.236 & 30.676 \\
\hline Antigua y Barbuda & -340 & -356 & -383 & -379 & -384 & -413 & 380 & 377 & 416 & 1 & -7 & 3 \\
\hline Argentina & 13.003 & 14.574 & 17.294 & 7.412 & 7.034 & 8.816 & 4.188 & -10.724 & -8.323 & 11.600 & -3.690 & 493 \\
\hline Bahamas & -1.135 & -1.060 & -1.765 & -1.315 & -1.118 & -544 & 1.269 & 1.228 & 919 & -46 & 109 & 375 \\
\hline Barbados & -227 & -379 & -923 & -182 & -363 & -187 & 461 & 142 & $\ldots$ & 276 & -221 & $\ldots$ \\
\hline Belice & 17 & -105 & -220 & -52 & -150 & -80 & 75 & 208 & 130 & 23 & 58 & 50 \\
\hline Bolivia & 815 & 1.267 & 440 & 1.591 & 2.015 & 1.063 & 361 & 369 & -332 & 1.952 & 2.374 & 731 \\
\hline Brasil & 26.813 & 8.146 & 10.100 & 1.551 & -28.192 & -18.418 & 85.933 & 31.161 & 55.758 & 87.484 & 2.969 & 37.340 \\
\hline Chile & 22.660 & 8.200 & 12.110 & 7.189 & -3.440 & 2.908 & -10.403 & 9.884 & 1.047 & -3.214 & 6.444 & 3.955 \\
\hline Colombia & -3.203 & -2.075 & -2.350 & -5.819 & -6.857 & -6.247 & 10.490 & 9.412 & 7.396 & 4.672 & 2.555 & 1.149 \\
\hline Costa Rica & -1.251 & -2.784 & -640 & -1.646 & -2.732 & -1.195 & 2.794 & 2.384 & 1.462 & 1.148 & -348 & 267 \\
\hline Cuba & 1.647 & $\ldots$ & $\ldots$ & 488 & $\ldots$ & $\ldots$. & $\ldots$ & $\ldots$ & $\ldots$ & $\ldots$ & $\ldots$ & $\ldots$ \\
\hline Dominica & -90 & -115 & -116 & -85 & -112 & -114 & 84 & 109 & 133 & -1 & -3 & 19 \\
\hline Ecuador & 452 & -270 & -2.810 & 1.650 & 1.120 & -1.603 & -264 & -172 & 1.725 & 1.387 & 948 & 122 \\
\hline El Salvador & -4.395 & -4.978 & -3.324 & -1.121 & -1.682 & -524 & 1.502 & 2.016 & 644 & 280 & 334 & 120 \\
\hline Granada & -251 & -2.79 & -268 & -261 & -289 & -281 & 271 & 283 & 278 & 11 & -6 & -3 \\
\hline Guatemala & -5.797 & -5.944 & -4.325 & -1.786 & -1.863 & -628 & 2.002 & 2.195 & 514 & 216 & 333 & -114 \\
\hline Guyana & -465 & -502 & -350 & -189 & -299 & -195 & 188 & 306 & 428 & -1 & 7 & 233 \\
\hline Haití & -1.513 & -2.058 & -1.868 & 7 & -277 & -68 & 148 & 374 & 64 & 154 & 98 & -4 \\
\hline Honduras & -3.249 & -4.647 & -3.087 & -1.225 & -1.977 & -1.129 & 1.063 & 1.912 & 374 & -162 & -65 & -755 \\
\hline Jamaica & -3.417 & -4.375 & -2.800 & -2.038 & -2.794 & -700 & 1.598 & 2.689 & 836 & -440 & -105 & 136 \\
\hline México & -16.379 & -24.340 & -13.612 & -8.335 & -15.806 & -6.074 & 18.621 & 23.244 & -1.422 & 10.286 & 7.438 & -7.496 \\
\hline Nicaragua & -1.941 & -2.420 & -1.634 & -1.001 & -1.513 & -818 & 1.093 & 1.499 & 1.024 & 92 & -14 & 207 \\
\hline Panamá & -365 & -1.452 & -506 & -1.422 & -2.792 & -1.974 & 2.044 & 3.377 & 2.124 & 622 & 584 & 150 \\
\hline Paraguay & -11 & -650 & -380 & 200 & -471 & -205 & 523 & 850 & 1.035 & 723 & 379 & 830 \\
\hline Perú & 7.099 & 1.161 & 2.873 & 1.220 & -4.180 & -1.224 & 8.368 & 7.292 & 3.676 & 9.528 & 3.112 & 2.452 \\
\hline R. Dominicana & -3.419 & -6.054 & -3.973 & -2.096 & -4.437 & -2.353 & 2.716 & 4.117 & 2.230 & 620 & -320 & -123 \\
\hline Saint Kitts y Nevis & -112 & -153 & -149 & -110 & -131 & -151 & 117 & 145 & 221 & 7 & 15 & 70 \\
\hline San Vicente & -189 & -216 & -204 & -190 & -217 & -209 & 188 & 213 & 211 & -2 & -3 & 3 \\
\hline Santa Lucía & -272 & -214 & -186 & -327 & -272 & -244 & 345 & 269 & 292 & 19 & -3 & 48 \\
\hline Suriname & 250 & 236 & 270 & 336 & 344 & 280 & -148 & -302 & -9 & 177 & 52 & 271 \\
\hline Trinidad y Tabago & 6.268 & 9.679 & 6.788 & 5.364 & 8.792 & 5.247 & -3.824 & -6.086 & -7.000 & 1.541 & 2.706 & -1.753 \\
\hline Uruguay & 128 & -811 & 214 & -80 & -1.119 & -152 & 1.091 & 3.352 & 1.755 & 1.010 & 2.233 & 1.603 \\
\hline Venezuela & 16.027 & 37.302 & 10.403 & 18.063 & 37.392 & 7.986 & -23.805 & -28.117 & -17.686 & -5.742 & 9.275 & -9.700 \\
\hline
\end{tabular}

Fuente: FMI, CEPAL y gobiernos nacionales.

Los saldos de la balanza global se equilibran con la partida variación de activos de reserva (con signo negativo), que significa un incremento por ese monto de las reservas internacionales netas (RIN); si el signo es positivo, significa lo contrario. 
La tendencia a una contracción importante tanto en las exportaciones como en las importaciones fue clara y pareja para la gran mayoría de los países de la región. Diferenciando según la variación de precios y de volúmenes, demuestra que los países exportadores de commodities exhibieron una caída más profunda en los valores unitarios de sus exportaciones, en tanto que las reducciones en sus volúmenes fueron menos que en el caso de los países exportadores de bienes manufacturados. A su vez, los valores unitarios de las importaciones cayeron menos por cuanto exhiben un mayor contenido de manufacturas cuyos precios son normalmente menos sensibles a la situación de corto plazo del mercado.

Durante el 2009, el entorno financiero externo latinoamericano reflejó las consecuencias de los bruscos cambios originados en la crisis global. A raíz del significativo incremento generalizado de la incertidumbre en los mercados mundiales, Latinoamérica, así como el conjunto de los países emergentes, experimentaron una sustantiva alza en los premios por riesgo, salidas de capitales y suspensiones de líneas de crédito externo para los bancos de la región, estos factores se expresaron en reducciones de las reservas internacionales y aumentos en las tasas o tipos de cambio.

En el 2008 y el 2009, el déficit de la cuenta corriente latinoamericana ascendió a -26.767 y -19.429 millones de dólares, respectivamente, considerando que en ambos años se registró una balanza comercial favorable (mayor a los 14.000 millones de dólares); sin embargo, los movimientos de capital a corto y largo plazo (balanza de capital y financiera), registran volúmenes mayores de recursos externos aunque de manera decreciente, así en el 2008, dicho monto ascendió a 63.993 millones de dólares y en el 2009, a 49.920 millones de dólares; en ambos casos, estos monto superaron al déficit de la cuenta corriente obteniéndose saldos que incrementaron las reservas internacionales (ver, cuadro 3), sin lograr detener la disminución del total de las reservas.

\section{CONCLUSIONES}

a) La recuperación de la economía mundial ha sido desigual y las condiciones para un crecimiento sostenido siguen siendo frágiles. Debido a las condiciones crediticias restrictivas en las economías desarrolladas más grandes; al bajo nivel de incremento de la demanda interna en muchas economías que sigue siendo tentativo y está lejos de ser auto sostenido. Gran parte de la recuperación es resultado del estímulo fiscal fomentado por los gobiernos, así como al reabastecimiento de inventarios en las industrias. Sin embargo, la demanda de consumo e inversión sigue siendo débil, ya que las tasas de desempleo y subempleo siguen aumentando.

b) El número de desempleados sigue creciendo en la mayoría de las economías, en los EE.UU., la cifra de desempleados ha aumentado a más del doble desde el comienzo de la recesión; las tasas de desempleo en la región del euro y Japón también han aumentado notablemente. Las tasas de desempleo en las economías en desarrollo también han aumentado, aunque la mayoría de las pérdidas de empleo provienen de los sectores exportadores. Hay una preocupación creciente con respecto al marcado aumento en el empleo vulnerable y la pobreza entre los trabajadores.

c) Se espera que el impacto de la crisis global en las condiciones laborales empeore las brechas sociales en cuanto a oportu- 
nidades de empleo en los países en desarrollo. Esto afectará, en particular, a las mujeres, quienes suelen estar más involucradas en empleos temporales y trabajos en industrias manufactureras orientadas a la exportación. Tanto en países desarrollados como en desarrollo, un número creciente de universitarios recién graduados sigue enfrentando grandes dificultades para encontrar empleo.

d) A pesar de las políticas monetarias expansivas, la inflación se mantendrá en niveles bajos en los próximos años, debido al continuado incremento de las tasas de desempleo, las grandes brechas del producto y a que la demanda agregada se mantenga por debajo de la capacidad productiva. Al mismo tiempo, los incrementos adicionales en los precios de los productos primarios serán limitados; y las altas tasas de desempleo, aunadas a los esfuerzos del sector empresarial para reducir costos, mantendrá bajas las presiones salariales.

e) Las nuevas tendencias representan un peligro estructural para la reducción de la pobreza. La reducción de oportunidades de empleo e ingresos hará que se avance más lentamente en la reducción de la pobreza; por otro lado, es probable que los trabajadores que se hallan en el extremo inferior de la escala laboral, en particular los jóvenes y mujeres, quienes pierdan sus empleos o sufran pérdidas de ingresos. Asimismo, se esta poniendo de manifiesto la tendencia que los trabajadores abandonan los sectores dinámicos orientados a la exportación y o bien quedan desempleados o bien se ven desplazados a actividades de más baja productividad, que incluye el retorno a las zonas rurales desde zonas urbanas.

\section{REFERENCIAS BIBLIOGRÁFICAS}

1. Banco Central de Reserva del Perú (2010). Informe Macroeconómico: IV Trimestre de 2009. Resumen Informativo N. ${ }^{\circ} 8$.

2. Bárcena, Alicia (2009). En búsqueda de soluciones a la crisis financiera: medidas adoptadas y futuros desafios. Organización de Estados Americanos, Washington D.C.

3. Castro Herrera, Soraya (2008). La economía peruana en 2006 y el escenario internacional. Lima.

4. Comisión Económica para América Latina (2009). Balance preliminar de las economías de América Latina y el Caribe, 2008. Santiago de Chile.

5. Comisión Económica para América Latina (2010). Balance preliminar de las economías de América Latina y El Caribe, 2009. Santiago de Chile.

6. Herrera García, Beatriz (2008). La coyuntura internacional en 2008 y 2009. Revista Quipukamayoc, UNMSM, Lima.

7. Herrera García, Beatriz (2009). Evaluación de la coyuntura internacional ¿Lo peor de la crisis ha pasado? Lima.

8. International Labour Organization (ILO) (2009). Paper submitted to the ILO governing body comite on employment and social policy. Geneva.

9. Naciones Unidas (2008). Informe sobre los objetivos de desarrollo del milenio. Nueva York.

10. Naciones Unidas (2009). Global outlook. New York.

11. OECD (2009). Main economic indicators. París.

12. OIT (2009). The financial and economic crisis: A decent work response. Ginebra.

13. UN/DESA (2009). Cómo superar la inseguridad económica. Doha, Qatar. 
14. UN/DESA (2009). World economic situation and prospects 2008. Ginebra.

15. UN/DESA (2010). World economic situation and prospects 2009. Ginebra.

16. UN/Consejo Económico Social (2008). Situación y perspectivas para la economía mundial 2008. Nueva York.
17. UN/Consejo Económico Social (2009). Situación y perspectivas de la economía mundial a mediados de 2009. Ginebra.

18. UN/Consejo Económico Social (2010). Situación y perspectivas de la economía mundial 2010. Nueva York. 